\title{
PENERAPAN SYSTEM SINGLE SIGN ON DALAM AIRZONE-MALL PADA PERGURUAN TINGGI RAHARJA
}

\author{
Qurotul Aini ${ }^{1}$ \\ Sugeng Santoso ${ }^{2}$ \\ Riska Laina Ulfa ${ }^{3}$ \\ Dosen STMIK Raharja ${ }^{1,2}$ \\ STMIK Raharja Jurusan Sistem Informasi ${ }^{3}$ \\ Jl. Jendral Sudirman No. 40, Modernland, Kota Tangerang ${ }^{1,2,3}$ \\ Email: aini@raharja.info ${ }^{1}$, sugeng.santoso@ raharja.info ${ }^{2}$, ${\text { riska@ } \text { raharja.info }^{3}}^{3}$
}

\begin{abstract}
ABSTRAK
Semakin berkembangnya teknologi maka banyaknya sistem yang semakin berkualitas, yang menjadikan sistem kerja lebih mudah. Sebagai Perguruan Tinggi yang bergerak dibidang Teknologi, Raharja memiliki website mall online yang disebut dengan AirzonE-Mall merupakan sebuah Mall Online dengan tujuan sebagai media pembelajaran bagi para mahasiswa/i untuk mengembangkan bakat Enterpreneur diusia remaja yang khususnya bagi Pribadi Raharja. Maka dari itu diperlukannya Single Sign On (SSO) untuk meminimalisir masuknya penggunaaan akun selain Rinfo. Dengan menggunakan SSO Rinfo, Pribadi Raharja hanya cukup melakukan autentikasi sekali saja tanpa menggunakan User Name dan Password. Hal ini dapat mempermudah pengorganisasian data pengguna sehingga keamanan data pengguna lebih terjamin.
\end{abstract}

Kata kunci : AirzonE-Mall, Single Sign On (SSO), E-Commerce

\begin{abstract}
Growing technology then the multitude of increasingly quality system, which makes the system work much easier. As the College engaged in technology, online mall website Raharja has called the AirzonE-Mall is a Mall Online with a goal as a medium of instruction for students/i to develop the talents of Some diusia teenagers especially for Private Raharja. Hence the need for Single Sign On (SSO) to minimize the entry of its account in addition to Rinfo. Using SSO Rinfo Private Raharja, just simply do authentication just once without using a User Name and Password. This can simplifyorganizing user data so that the security of user data more secure.
\end{abstract}

Keywords: AirzonE-Mall, Single Sign On (SSO), E-Commerce

\section{PENDAHULUAN}

Teknologi informasi sekaranng ini dibuat untuk mempermudahkan para penjualan, tidak perlu lagi tanah dan bangunan atau outlet yang tentunya membutuhkan modal lebih banyak. Saat ini sudah sangat pepuler berjualan di media internet atau Online shopping. Dalam dunia bisnis teknologi informasi mempunyai dampak yang besar, misalnya suatu transaksi bisnis yang dicatat 
secara on-line pastinya lebih memudahkan bagi para pengguna. Dan diolah pada saat yang bersamaan (Real-Time).

Pada saat ini informasi menjadi hal yang sangat penting dalam kegiatan berbisnis, dengan dukungan teknologi informasi, informasi semakin mudah diperoleh tanpa dibatasi ruang dan waktu serta kapanpun dan dimanapun.

Web ataupun situs media sosial merupakan sarana yang sangat efektif untuk kegiatan marketing communication. Banyaak masyarakat beralih ke dunia bisnis berbasis online. Alasanya, Apapun segala promosi dapat dilakukan dengan sangat mudah, cepat, dan gratis. Beberapa contoh layanan berbasis web 2.0 adalah situs jejaring sosial seperti Facebook, Twitter, Instagram dan Youtube.

Perguruan Tinggi Raharja merupkan salah satu pendidikan yang bergerak di bidang teknologi informasi. Untuk itu, Perguruan Tinggi Raharja terus menerus melakukan peningkatan serta pengembangan berupa sistem pembelajaran degan online, khususnya bagi Mahasiswa/I iLearning dalam kampus yang ditetapkan di Perguruan Tinggi Raharja. Dengan adanya sistem pembelajaran online ini, mahasiswa/i diharapkan dapat memiliki wawasan yang lebih luas lagi.

\section{PERMASALAHAN}

Berdasarkan permasalahan dan Analisa diatas, maka dapat disimpulkan membahas beberapa permasalahan,

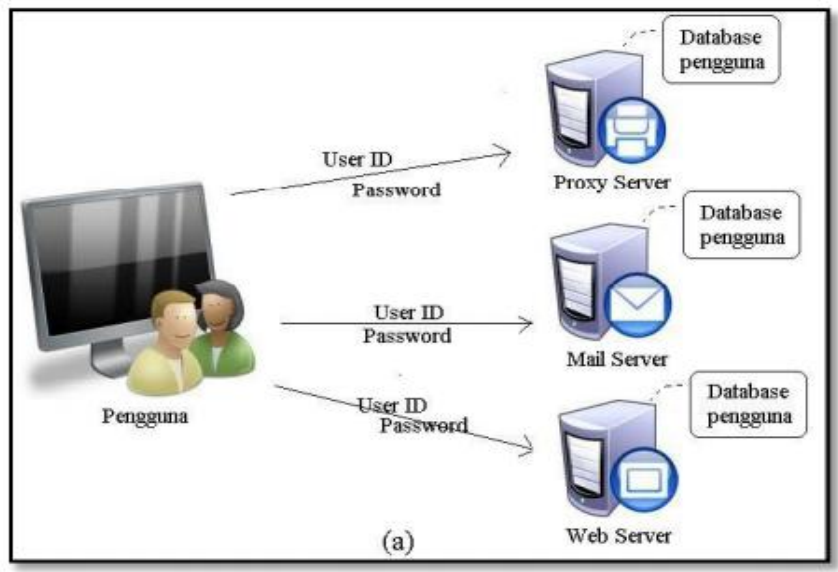

Gambar 1. Sistem Sign-On

(sumber: E-Book Universitas Sumatera)

Dalam sebuah website, tentunya tidak lepas dari persoalan keamanan. Ketika mengevaluasi keamanan sebuah website. Apalagi persoalan username dan password Karena banyak yang terjadi lupa username ataupun lupa password. Maka dari itu perlu adanya Sistem Single Sign On .

Selain untuk keamanaan dan kemudahan, Sistem Single Sign On ini hanya dipergunakan dalam ruang lingkup Perguruan Tinggi Raharja.

\section{LANDASAN TEORI}

SSO (Single Sign On) merupakan teknologi yang memiliki kemampuan untuk memasukkan id dan password yang sama untuk login ke beberapa website. password merupakan 
mekanisme otentikasi paling aman. Untuk jaringan yang sangat besar dan bersifat heterogen, dimana pengguna diminta untuk mengisi informasi data diri pada setiap aplikasi yang hendak di akses dibutuhkan SSO (Single Sign On). Sistem SSO (Single Sign On) tidak memerlukan interaksi yang manual, untuk mengakses seluruh layanan aplikasi tanpa harus melakukan login dan mengetikan password-nya berulang-ulang. SSO (Single Sign On) meng-otentikasi pengguna pada semua aplikasi yang telah diauthorized untuk diakses. (Gilang Ramadhan 2013 kutipan dari, Rudi 2009) SSO (Single Sign On) juga memperkenankan informasi autentikasi dan mengidentifikasi subjek secara ketat guna menghindari login ganda pada sistem. Sistem SSO (Single Sign On) juga dapat memusatkan penglolaan dari parameter sistem yang relevan pada saat bersamaan dan meningkatkan penggunaan secara keseluruhan. Pengguna layanan bisa lebih menyukai sistem SSO (Single Sign On) dari pada sistem Sign-on biasa

\section{LITERATURE REVIEW}

Banyak penelitian yang sebelumnya dilakukan mengenai perihal Online Shopping serta Single Sign On (SSO). Dalam upaya pemanfaatannya Single Sign On (SSO) pada AironE-Mall ini perlu dilakukan studi pustaka (literature review) sebagai salah satu dari penerapan metode penelitian yang akan dilakukan. Diantaranya adalah mengidentifikasikan kesenjangan (identify gaps), menghindari pembuatan ulang (reinventing the wheel), mengidentifikasikan metode yang pernah dilakukan, meneruskan penelitian sebelumnya, serta mengetahui orang lain yang spesialisasi dan area penelitiannya sama dibidang ini. Beberapa Literature review tersebut adalah sebagai berikut :

1. Penelitian Jurnal Ilmiah yang dilakukan oleh Untung Rahardja, M.T.I, Iqbal fadillah dan Wulan Lestari dari Perguruan Tinggi Raharja, "Penggunaan System Single Sign On (SSO) Dalam Mendukung Kemajuan Pada Forum RhjFox Di Perguruan Tinggi Raharja" RhjFox yang dijadikan sebagi wadah untuk saling berdiskusi atau bertukar pikiran antar Pribadi Raharja. meskipun RhjFox telah memiliki banyak anggota namun masuh terdapat beberpa kendala diantaranya anggota sulit untuk melakukan login. Untuk mengatasi masalah seperti yang dijelaskan diatas, maka dibuatlah system Single Sign On (SSO) untuk lebih mempermudah anggota dalam melakukan login tanpa harus menggunakan password. Dan dengan merumuskan penggunaan SSO pada register atau login RhjFox hal ini dimungkinkan dengan menggunakan metode SWOT untuk pencapaian sebuah masalah. Diharapkan dengan menggunakan system Sigle Sign On (SSO) dapat lebih mempermudah anggota untuk mengakses maupun mencari informasi kegiatan RhjFox yang ada di database melalui viewbord serta memiliki Rank yang cukup ideal. Hal ini dapat mempermudah pengguna dalam menggunakan aplikasi yang ada, sehingga keamanan data pengguna lebih terjamin.

2. Penelitian yang dilakukan oleh Amiudin, dari Universitas Muhammadiah Malang pada tahun 2014 dengan judul "Implementasi Single Sign On (SSO) Untuk mendukung Interaktifitas Aplikasi E-Commerce Menggunakan Protocol Oauth" Penelitian ini menjelaskan mengenai hal yang terkait dengan membangun aplikasi Single Sign On (SSO) dengan menggunakan SSO, pengguna dapat mengakses hanya dengan sekali untuk mendapatkan izin. Akses kesemua yang terdapat dalam jaringan.

3. Penelitia yang dilakukan oleh Vignasari (2016) "Clustering Penggunaan Bandwidth Menggunakan Metode K-means Algorithm Pada Penerapan Single Sign On (SSO) Universitas Sebelas Maret" Akses internet melalui sistem Single Sign On (SSO) di Universitas Sebelas Maret telah banyak di manfaatkan oleh civitas akademik seperti 
mahasiswa dan karyawan/dosen. Data dari aktifitas penggunaan SSO tersebut tercatat pada log SSO dan telah terkumpul banyak. Pada log tersebut tercatat mengenai: (1) status perangkat jaringan yang di gunakan, (2) riwayat login pengguna dan (3) riwayat logout pengguna SSO. Pada riwayat login dan logout pengguna terdapat detail data seperti akun pengguna, lokasi dan tanggal mengakses, jumlah penggunaan bandwidth download dan upload, waktu login dan waktu logout. Teknik data mining dapat di terapkan untuk menggali informasi dari data log SSO yang telah terkumpul banyak. Tujuan penelitian ini untuk menganalisa penggunaan bandwidth Universitas Sebelas Maret (UNS) berdasarkan data trafik internet dari log SSO dengan menggunakan metode data clustering untuk mengelompokkan data yang mempunyai kesamaan dalam satu cluster, yaitu menggunakan algoritma.

4. Penelitian ini dilakukan oleh Untung Rahardja, Qurotul Aini dan Desi Sartika dari Perguruan Tinggi Raharja pada tahun 2014 yang berjudul "Build A Business To Consumer Online Store Using Airzone Content Management System". Penelitian ini membahas mengenai Sistem Jual Beli Online Airzone yang menerapkan Sistem E-Commerce yang menghubungkan antara 4 (empat) Klasifikasi E-Commerce menurut pola interaksi atau transaksi yaitu Costumer-toBusiness (C2B), Business-to-Costumer (B2C), Business-to-Business (B2B) dan Peer-to-Peer (P2P). Dengan adanya Sistem E-Commerce tersebut mempermudah konsumen dan masyarakat untuk berbelanja secara online di Airzone menjadi lebih Efektif dan Efisien.

5. Penelitian dilakukan oleh Achmad Solihin pada tahun 2011. Penelitian ini mengenai "System and method for single sign-on to a plurality of network elements" A secured network permits a single sign-on ("SSO") of users to a plurality of network elements. Data structures, procedures and system components that support the SSO functionality in a distributed networked environment are included in the secured network. The SSO functionality can be implemented and integrated into an existing network platform or used as the backbone protocol to new network installations. DCE-based features as well as ERA and EAC can be utilized as the foundation for the implementation. The SSO functionality may be implemented and integrated without requiring significant low level development or major modifications in a network.

6. Penelitian yang dilakukan oleh Rudy, Riechie, Odi Gunadi. Penelitian ini mengenai "INTEGRASI APLIKASI MENGGUNAKAN SINGLE SIGN ON BERBASISKAN LIGHTWEIGHT DIRECTORY ACCESS PROTOCOL (LDAP) DALAM PORTAL". pengimplementasian metode Single Sign On (SSO) dengan menggunakan Central Authentication Service (CAS) dan Lightweight Data Access Protocol (LDAP) di dalam Web Portal Bina Nusantara. Tujuan utama dari pengimplementasian SSO ini adalah untuk menggabungkan aplikasi yang ada pada binus-access ke dalam sebuah site sehingga terbentuk integrasi aplikasi, khususnya dalam bentuk web yang biasa disebut dengan Web Portal. Dengan adanya Web Portal yang menggunakan metode Single Sign On (SSO) ini, berarti setiap user hanya perlu memiliki satu username, satu password. Dan bila ingin mendapatkan layanan atau fasilitas di Web Portal, user ini hanya perlu login satu kali saja bisa dapat menggunakan semua fasilitas atau layanan aplikasi yang ada di dalam Web Portal tersebut.

7. Penelitian ini dilakukan oleh Qurotul Aini, Indri Handayani dan Cahyo Anggoro Seto pada Perguruan Tinggi Raharja 2015 yang berjudul "Content Management System ZPreneur In Support Of Entrepreneurship iLearning At Perguruan Tinggi Raharja". Penelitian ini membahas mengenai Penerapan Content Management System Ecommerce ZPreuner dalam mendukung kegiatan entrepreneurship mahasiswa di Perguruan Tinggi Raharja merupakan 
solusi yang terbaik. Sistem ZPreuner merupakan sebuah sistem ecommerce berbasis web yang mampu membantu mahasiswa dalam melakukan kegiatan entrepreneur.

Dari 8 (delapan) literature review yang ada, telah banyak pendapat perihal penggunaan sistem Single sign Out (SSO). Dengan begitu memudahkan para pengguna atau user untuk melakukan log-in. Dan dapat mengakses kebanyak layannan yang ada dengan cepat.

\section{PEMECAHAN MASALAH}

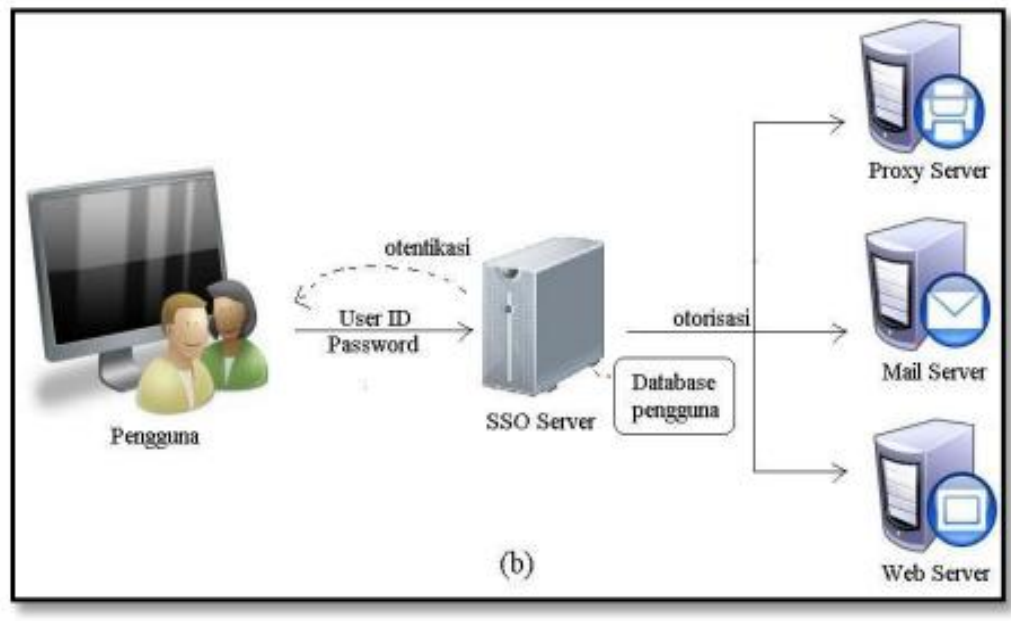

Gambar 2. Sistem Single Sign On

(Sumber : E-Book Universitas Sumatera)

Perguruan Tinggi Raharja sebagai salah satu instansi atau lembaga pendidikan yang bergerak di bidang IT (Information Technologi) yang terus berinovasi dalam menciptakan media system informasi untuk kebutuhan sehari-hari. Dalam suatu sistem media informasi penyampaiannya masih menggunakan website, baik itu secara personal maupun teamwork.

AirzonE-Mall pertama kali muncul dari ide Ir. Untung Raharja, M.T.I dan Qurotul Aini S.Kom yang merupakan sebuah Mall Online dengan tujuan sebagai media pembelajaran bagi para mahasiswa Perguruan Tinggi Raharja dalam dunia e-commerce dimana AirzonE-Mall membantu para remaja diusia produkktif untuk bisa menjadi seller yang sukses dan buyer smart. Pada AirzonE-Mall, mahasiswa yang sudah melakukan daftar disebut User dan User tersebut dapat membuat sebuah toko atau store yang sebagai Vendor.

Setelah meninjau dari sudut permasalahan yang telah terjadi di dalam sistem yang sudah berjalan, penulis memiliki beberapa pilihan alternatif pemecahan masalah untuk persoalan pada sistem yang berjalan, yaitu sebagai berikut:

1. Dengan adanya sistem Single Sign On dapat Menciptakan dengan hanya memiliki sebuah Account E-Mail yang telah diaktifksn. Maka pengguna bisa mengakses fasilitas lainnya dengan hanya satu Account. 


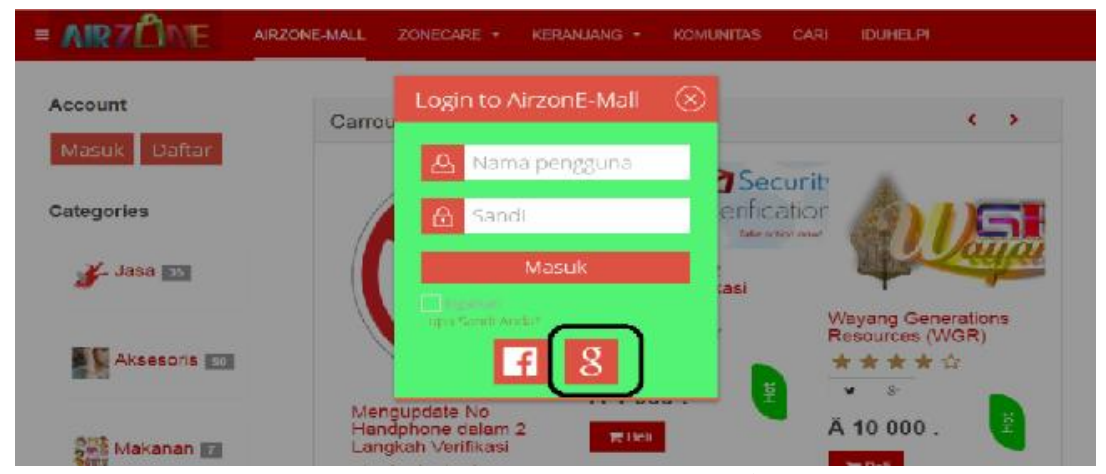

Gambar 3, Login system Single Sign Out

(Sumber : http://airzone.zpreneur.org )

2. User tidak perlu mengingat banyak username dan password.

3. Kemudahan pemrosesan data. Jika setiap server memiliki data user masing-masing, maka pemrosesan data user (penambahan, pengurangan, perubahan) harus dilakukan pada setiap server yang ada. Sedangkan dengan menggunakan SSO, cukup hanya melakukan 1 (satu) kali pemrosesan.

4. Adanya sistem yang dapat digunakan dimana saja, kapan saja dan tidak membutuhkan waktu yang lama.

Dengan diterapkannya sistem Single Sign On dalam jaringan yang sangat besar dan bersifat heterogen (di saat sistem operasi serta aplikasi yang digunakan oleh komputer adalah berasal dari banyak vendor, dan pengguna dimintai untuk mengisi informasi dirinya ke dalam setiap platform yang berbeda tersebut yang hendak diakses oleh pengguna). Dengan menggunakan SSO, seorang pengguna hanya cukup melakukan proses autentikasi sekali saja untuk mendapatkan izin akses terhadap semua layanan yang terdapat di dalam jaringan.

\section{Keistimewaan AirzonE-Mall}

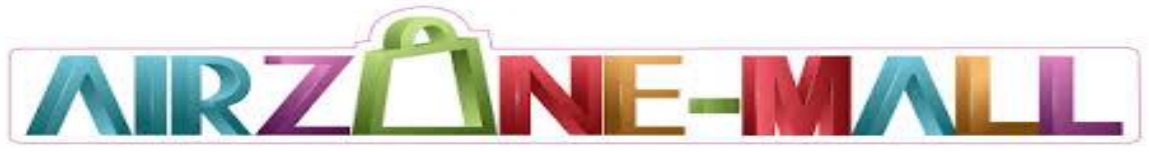

Gambar 4, Logo AirzonE-Mall

(Sumber : http://airzone.zpreneur.org )

AirzonE-Mall memiliki slogan yaitu "Enjoy Shopping Anywhere and Anytime" yang berarti AirzoE-Mall itu sangat mudah terjangkau mau kapanpun dan dimanapun kita berada AirzonE-Mall dapat diakses karena bersifat online dan hanya di khususkan untuk Pribadi Raharja. Terdapat 5 (lima) keuntungan yang didapat saat bergabung dengan AirzonE-Mall:

Rp 0,-

Dengan Rp 0,- untuk dapat membuat toko atau store di AirzonE-Mall. Karena tujuan dasar dari AirzonE-Mall adalah pembelajaran bukan uang. Pengembangan diri dari para user dan vendor di AirzonE-Mall dalam hal e-commerce lebih utama.

ZPreneur

Selain menyediakan fasilitas untuk melakukan transaksi jual-beli online, tersedia juga komunitas online yang disebut dengan ZPreneur. Dimana ZPreneur menjadi wadah bagi para user dan vendor untuk saling berbagi banyak informasi dengan hal yang positif. 
ZPreneur sendiri menggunakan teknik gemifikasi, dan di dalam ZPreneur kita bisa saling Send Gift sesama ZPer's.

Mata Uang ARMO

AirzonE-Mall memiliki mata uang sendiri yang disebut ARMO (AirzonE-Mall Money) yang di dapat dari aktifitas dalam ZPreneur. Kemudian di reedem sehingga dapat digunakan untuk bertransaksi di AirzonE-Mall.

Login dengan SSO (Single Sign On)

Dengan adanya SSO dapat memudahkan para pengguna AirzonE-Mall untuk melakukan

Login dengan Magic Key Rinfo.

IDuHelp!

Saat beraktifitas dan menghadapi kendala di AirzonE-Mall, tersedia iDuHelp! yang bisa digunakan untuk mendapatkan bantuan baik secara online maupun offline.

\section{Tujuan Airzon E-Mall}

Terciptanya sebuah website AirzonE-Mall ini bertujuan untuk meningkatkan para mahasiswa/i untuk belajar Enterpreneur serta memudahkan untuk melakukan implementasi di AirzonE-Mall khususnya bagi para Pribadi Raharja, serta untuk meningkatkan wawasan dan pengetahuan seputar dunia bisnis, dan untuk mengembangkan kreatifitas Pribadi Raharja didalam dunia Bisnis, untuk mendapatkan informasi mengenai Entrepreneurship bagi para Pribadi Raharja.

\section{Definisi Armo}

Armo (AirzonE-Mall Money) merupakan mata uang AirzonE-Mall yang diciptakan oleh mahasiswa Perguruan Tinggi Raharja. Armo (AirzonE Money) tercipta karena terinspirasi dari sebuah permainan monopoli, awal mula AirzonE-Mall ingin mempunyai mata uang seperti yang dimiliki permainan monopoli yang memiliki mata uang sendiri yang ditaruh di bank dari situlah mata uang AirzonE-Mall lahir lalu diberi nama Armo. Dengan adanya Armo diharapkan dapat memudahkan para pelajar untuk bisa bertransaksi di AirzonE-Mall dan Armo menjadi ciri khas tersendiri untuk AirzonE-Mall dan ZPreneur.

\section{IMPLEMENTASI}

Implementasi dilakukan dengan membuat proses login/logout aplikasi web seperti pada perancangan. Dimulai dengan persiapan sistem operasi, CAS Server dan Joomla!, hal terpenting yang harus dilakukan adalah melakukan konfigurasi agar semua proses dapat berjalan dengan hasil yang baik.

Saat ini tampilan website telah Login menggunakan dengan SSO Rinfo atau Gmail dan kita dapat mengakses semua fitur menu yang terdapat pada website AirzonE-Mall dengan sangat mudah. Karena telah ter-autentik

- Gambaran login dengan flowchart 


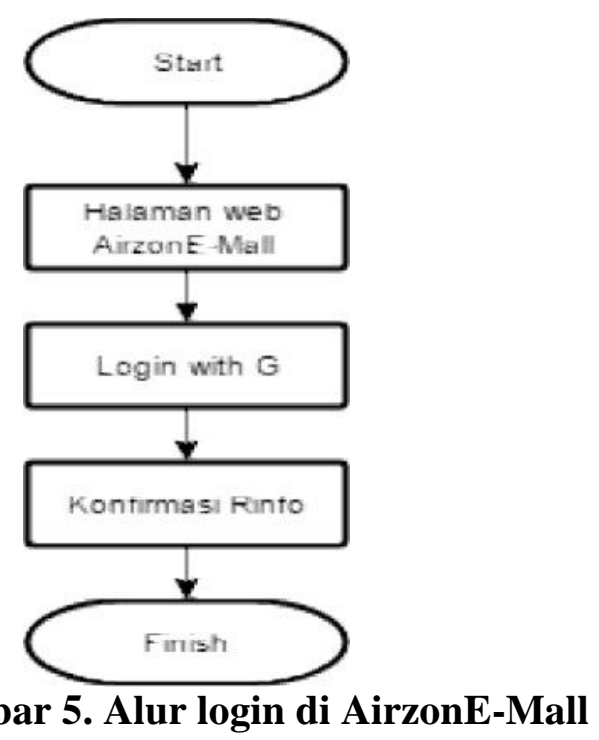

Dari Gambar 5. Diatas dapat dijelaskan sebagai berikut :

1. 2 (dua) simbol terminator sebagai simbol "start" dan "finish" pada aliran proses flowchart pada sistem SSO.

2. 3 (tiga) simbol proses dari "Masuk halaman web AirzonE-Mall" lakukan "Login with G" kemudian "Konfirmasi Rinfo"

1. Login: Langkah awal untuk menjelajahi website AirzonE-Mall

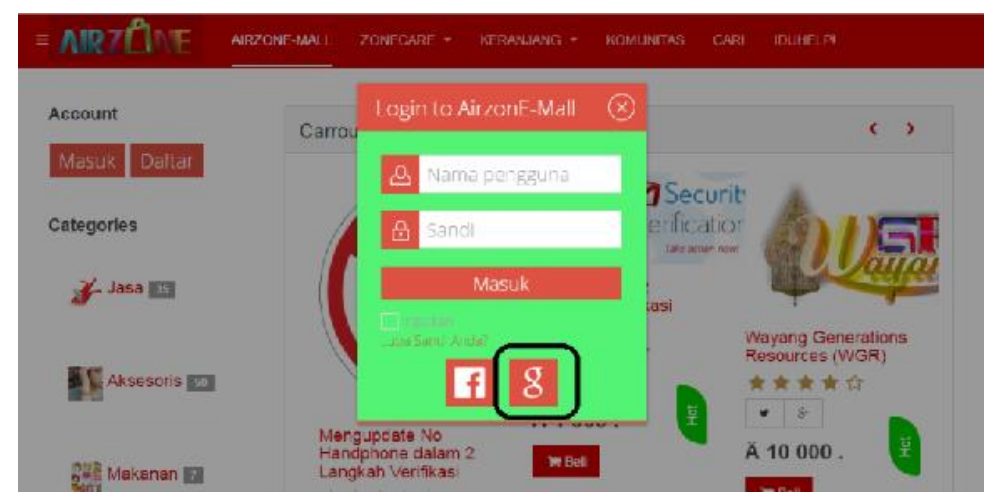

Gambar 6. Tampilan Login AirzonE-Mall

(Sumber : http://airzone.zpreneur.org )

2. Home: Tampilan halaman utama yang isinya untuk para Mahasiswa/I melakukan jualbeli barang maupun jasa. 

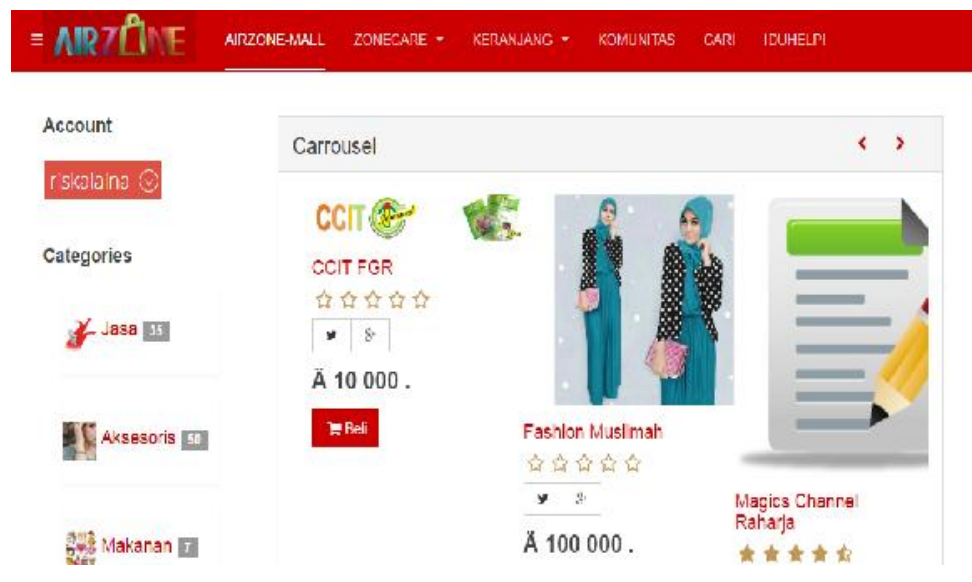

Gambar 7. Tampilan Home AirzonE-Mall

(Sumber : http://airzone.zpreneur.org)

A. Zonecare : Berisikan My Account dan Dashboard

- My Account merupakan profile penjelajah (Vendor)

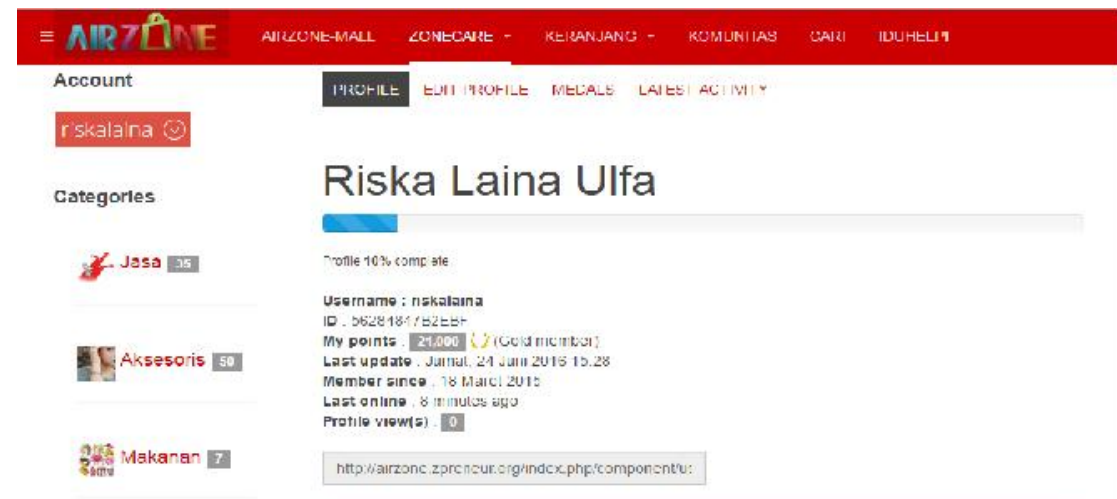

Gambar 8. Tampilan My Account

(Sumber : http://airzone.zpreneur.org)

- Dashboard merupakan halaman utama si penjual

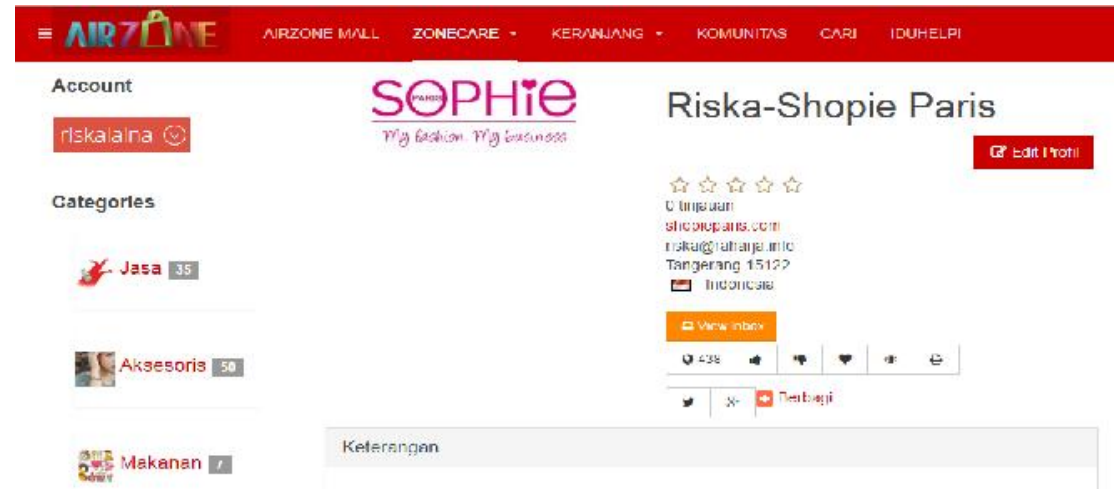

Gambar 9, Tampilan halaman Dashboard

(Sumber : http://airzone.zpreneur.org ) 
3. Keranjang berisikan daftar belanja untuk proses penjualan

- Terdapat button Rumah, Pelanggan, Katalog, Penjualan, Zona, Pembayaran

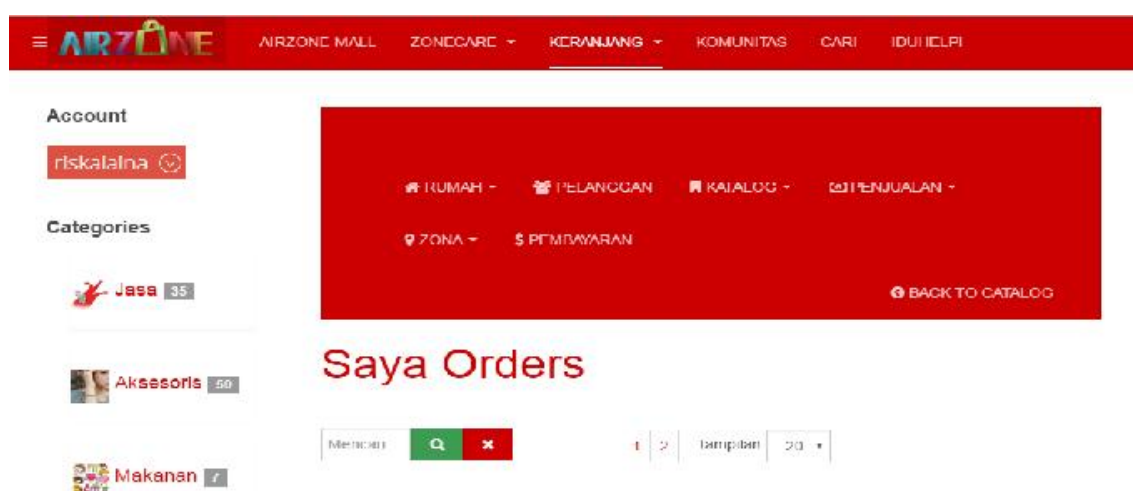

Gambar 10, Tampilan halaman Daftar Belanja

(Sumber : http://airzone.zpreneur.org)

4. Komunitas berisikan Zpreneur yang merupakan sebuah Website Komunitas Online yang menjadi wadah berkumpulnya Mahasiswa/i yang ingin bertukar informasi, berdiskusi dan bertukar pikiran tentang dunia bisnis.(http://zpreneur.org/)

- Zpreneur dapat Reedem Armo: Berisi tentang cara mereedem Armo untuk ditukarkan menjadi Voucher Belanja atau bertransaksi di AirzonE-Mall.
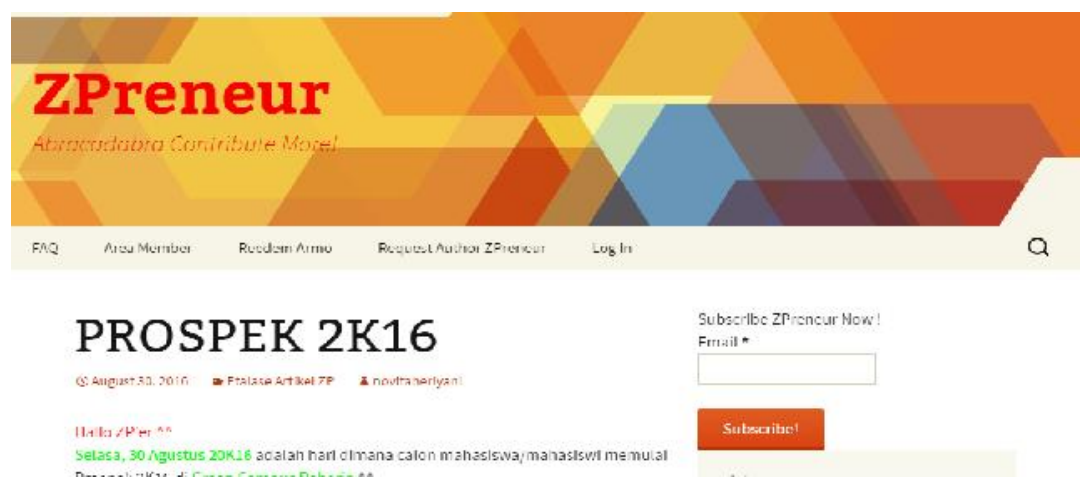

Gambar 11, Tampilan dari komunitas Zpreneur

(Sumber : http://zpreneur.org/)

5. Cari : berisikan memudahkan untuk penjelajah mencari apa yang diinginkan 


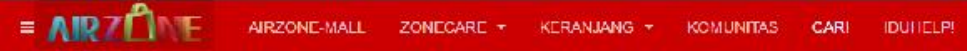

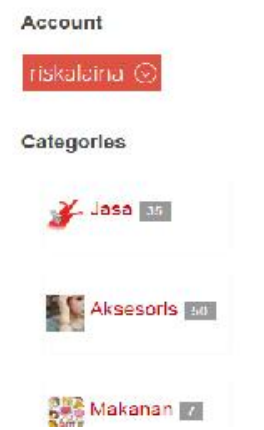

\section{Cari}

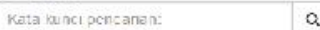

Pencarian untuk:

- Semua kata solah satu kato frase yang tepat

Urutan: levesua :

Cari hanya:

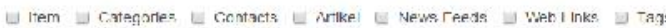

Gambar 12, Tampilan halaman pencarian

(Sumber : http://airzone.zpreneur.org )

6. IDuHelp! Saat beraktifitas dan menghadapi kendala di AirzonE-Mall, tersedia iDuHelp! yang bisa digunakan untuk mendapatkan bantuan baik secara online maupun offline.

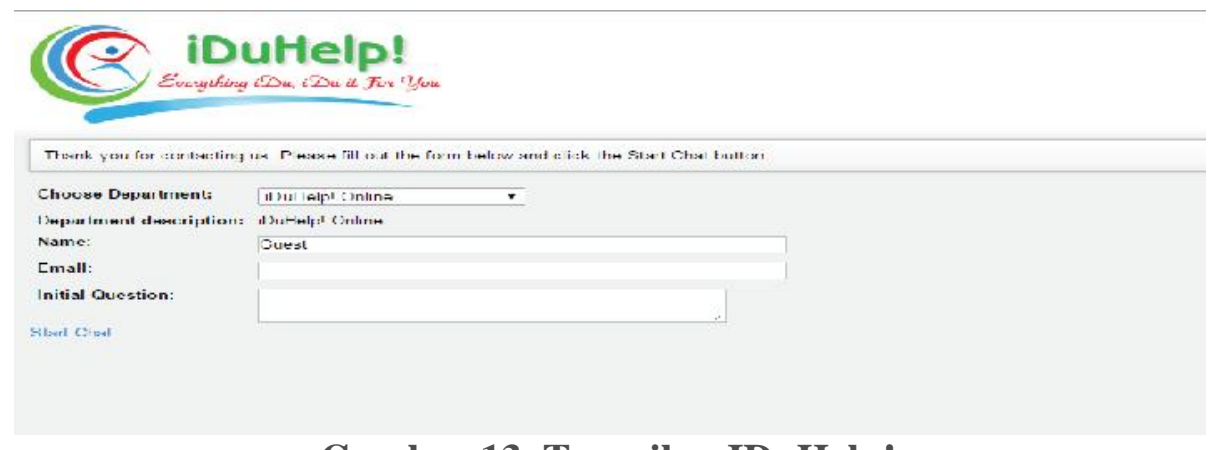

\section{Gambar 13, Tampilan IDuHelp!}

(Sumber : http://iduhelp.ilearning.me/ )

\section{KESIMPULAN}

Berdasarkan uraian diatas, dapat disimpulkan bahwa menerapkan sistem Single Sign On (SSO) yang digunakan pada website AirzonE-Mall pada Perguruan Tinggi Raharja tentunya memudahkan para pengguna user khususnya para Pribadi Raharja untuk melakukan login dengan Magic Key Rinfo.

Seperti kebanyakan pengguna user yang sering kali lupa password dan username akan sulit untuk memulihkannya untuk masuk kedalam website AirzonE-Mall. Dengan adanya system Single sign On ini diharapkan agar lebih efektif dan efisien bagi para Zp'er.

Single sign-on (SSO) adalah sebuah proses autentikasi user yang mengijinkan user untuk menyediakan sebuah credential yang telah di-authorized untuk diakses. Single sign on (SSO) dalam sebuah lingkungan jaringan biasanya menyimpan credentials dalam sebuah server terpusat atau dalam sebuah direktori. 


\section{DAFTAR PUSTAKA}

[1] Wikipedia. Definisi Single Sign On. Diakses pada tanggal 1 Agustus 2016. Tersedia di https://id.wikipedia.org/wiki/Single-sign-on

[2] Widuri. AirzonE-Mall. Diakses pada tanggal 1 Agustus 2016. Tersedia di http://widuri.raharja.info/index.php/AirzonE-Mall

[3] Dikutip dari IT Comuniti Indonesia. Pada tanggal 15 Agustus 2016, Tersedia di https://itcomindonesia.wordpress.com/kolom-it/network/single-sign-on-sso/

[4] Rudy, Riechie, Odi Gunadi "INTEGRASI APLIKASI MENGGUNAKAN SINGLE SIGN ON BERBASISKAN LIGHTWEIGHT DIRECTORY ACCESS PROTOCOL (LDAP) DALAM PORTAL” BINUS@CCESS (BEE-PORTAL)

[5] Rahardja, Untung, Qurotul Aini, and Desi Sartika. "BUILD A BUSINESS TO CUSTOMER ONLINE STORE USING AIRZONE CONTENT MANAGEMENT SYSTEM."

[6] Rahardja, Untung M.T.I, Iqbal fadillah dan Wulan Lestari dari Perguruan Tinggi Raharja, "Penggunaan System Single Sign On (SSO) Dalam Mendukung Kemajuan Pada Forum RhjFox Di Perguruan Tinggi Raharja"

[7] Amiudin, dari Universitas Muhammadiah Malang pada tahun 2014 dengan judul "Implementasi Single Sign On (SSO) Untuk mendukung Interaktifitas Aplikasi ECommerce Menggunakan Protocol Oauth"

[8] Vignasari (2016) "Clustering Penggunaan Bandwidth Menggunakan Metode K-means Algorithm Pada Penerapan Single Sign On (SSO) Universitas Sebelas Maret”.

[9] Padeli, Sudaryono dan Indri Handayani dari Perguruan Tinggi Raharja pada tahun 2014 yang berjudul "Building Marketing Untuk Komunitas Sendiri Berbasis Online".

[10] Solihin, Achmad. pada tahun 2011. Penelitian ini mengenai "System and method for single sign-on to a plurality of network elements".

[11] Aini, Qurotul. Indri Handayani dan Cahyo Anggoro Seto. CCIT Journal 2015 Content Management System ZPreneur In Support Of Entrepreneurship iLearning At Perguruan Tinggi Raharja. Perguruan Tinggi Raharja.

[13] Widuri. Armo. Diakses pada tanggal 8 Desember 2015. Tersedia di http://widuri.raharja.info/index.php?title=Armo

[14] Ramadhan, Gilang (2013). diakses pada tanggal 19 Januari 2016, Tersedia di http://eprints.binadarma.ac.id/ 